problems in children with epilepsy are sufficiently prevalent to warrant routine screening. The screening program in the Epilepsy Center at the Lurie Children's Hospital of Chicago has been expanded to include patients up to 18 years of age. The American Academy of Pediatrics recommends routine developmental and autism screening for all infants and toddlers. (AAP. Pediatrics 2001 Jul;108(1):192-6) (Filipek PA et al. Neurology 2000 Aug 22;55(4):468-79).

\title{
GAIT DETERIORATION IN ADOLESCENTS WITH DRAVET SYNDROME
}

Researchers at the University of Melbourne, Australia studied prospectively changes in gait by age in patients with Dravet syndrome. Of 26 patients aged 2 to 34 years, 15 were male and 11 female, mean age 11.6 years; 23 had SCN1A mutations. Children aged 0 to 5 years $(\mathrm{N}=7)$ had a normal gait, whereas 5 of 10 aged 6 to 12 years and 8 of 9 children aged 13 years or older had crouch gait. Ataxia was rarely observed in this cohort. Crouch gait is characterized by increased hip and knee flexion and ankle dorsiflexion, weakness in antigravity lower limb muscles, and without hypertonia or spastic cerebral palsy. Physical examination showed with increasing age, a decrease in passive knee extension and hip extension, and an increase in external tibial torsion and pes planovalgus. Increase in hip internal rotation showed no age-related change. The Functional Mobility Scale showed universal independent walking over 5 and $50 \mathrm{~m}$, whereas adolescents and adults showed wide variation in ratings over $500 \mathrm{~m}$, wheelchair use to independent walking. (Rodda JM, Scheffer IE, McMahon JM, Berrkovic SF, Graham HK. Progressive gait deterioration in adolescents with Dravet syndrome. Arch Neurol 2012 Jul;69(7):873-8). (Respond: Ingrid E Scheffer PhD, MBBS, Florey Neuroscience Institutes, Melbourne Brain Centre, 245 Burgundy Rd, Heidelberg, Melbourne, Victoria 3084, Australia. E-mail: scheffer@unimelb.edu.au).

COMMENT. Some reports estimate that $50 \%$ to $60 \%$ of Dravet syndrome patients have an ataxic gait (Korff C, Laux L, Kelley K, Goldstein J, Koh S, Nordli D Jr. J Child Neurol 2007 Feb;22(2):185-94). The cause of crouch gait in adolescents with Dravet syndrome in the present study is unclear, and the typical gait abnormality usually referred to as ataxic or spastic was absent. The authors speculate a possible relation to joint problems and planus foot deformity as precursors, and discuss the pros and cons of orthotic and surgical management. The impact of seizures, type of mutation, and anticonvulsants on the development of crouch gait are also suspect. Development of some connective tissue disorders (Dupuytren's contracture, general joint pain) is linked to treatment with anticonvulsant drugs, especially phenobarbital. (Mattson RH, Cramer JA, McCutchen CB. Arch Intern Med 1989 Apr;149(4):911-4).

\section{MRI ABNORMALITIES WITH FEBRILE STATUS EPILEPTICUS: THE FEBSTAT STUDY}

Researchers in the FEBSTAT Study Team at centers in New York, Durham, Virginia, and Chicago, IL report MRI findings in their prospective study of the acute effects of febrile status epilepticus (FSE) in 199 children age 1 month to 5 years. Patients 